\title{
NARRATIVA BIOGRÁFICA E ESCRITA DA HISTÓRIA: OCTÁVIO TARQUÍNIO DE SOUSA E SEU TEMPO*
}

\author{
Márcia de Almeida Gonçalves \\ Professora da UERJ e da PUC-RJ.
}

\section{Resumo}

O objetivo do artigo é analisar valores e concepções que informaram a discussão sobre os usos da biografia entre as narrativas historiográficas, tomando como referência textos assinados por Octávio Tarquínio de Sousa, nas décadas de 1930 a 1950.

\section{Pallavras-Chave}

Biografia $•$ História $・$ Modernismo • Estudos Brasileiros $・$ Historismo

\section{Abstract}

The objective of the article is to analyze the conceptions about the uses of biography and the writing of history, between 1930 and 1960, taking as reference texts signed by Octávio Tarquínio de Sousa.

\section{Keywords}

Biography • Historical Thought • Modernism • Brazilian Studies • Historicism

\footnotetext{
* Esse artigo corresponde a uma versão condensada de algumas análises realizadas em minha tese de doutorado - Em terreno movediço: biografia e história na obra de Octávio Tarquínio de Sousa - desenvolvida no programa de Pós-graduação da FFLCH/USP, área de História Social, sob a orientação do Prof. Dr. Elias Thomé Saliba.
} 
"Cada geração canta para ela própria e na sua linguagem" Alfred de Musset

Durante seu tempo de vida (1889-1959) e, em particular, na época em que realizou suas produções letradas, entre 1914 e 1958, Octávio Tarquínio de Sousa foi o autor dedicado ao estudo da história política brasileira $-1^{\circ}$ Reinado e Regências - por intermédio da escrita das biografias de alguns de seus dirigentes: Bernardo Pereira de Vasconcelos, Evaristo da Veiga, Diogo Antônio Feijó, José Bonifácio e D. Pedro I, elaboradas entre 1937 e 1952, ao fim reunidas na forma da coleção História dos Fundadores do Império do Brasil, em 1958. Além dessa marca autoral, vale esclarecer, a que mais foi sublinhada pela memória dos pósteros, Octávio Tarquínio participou intensamente dos círculos de sociabilidade intelectual que tanto imprimiram os ritmos da missão de redescobrir o Brasil, decantada por homens de letras e de ciências, a partir, notoriamente, de 1930.

Assim, entre outras atuações, foi diretor, de 1939 a 1959, da Coleção Documentos Brasileiros, publicada pela Livraria José Olympio Editora; colaborou, com regularidade, para o Suplemento Literário do jornal Correio da Manhã, entre 1947 e 1955; dirigiu a terceira fase da Revista do Brasil, entre 1938 e 1943; foi membro do conselho diretor da Sociedade Felipe D’Oliveira, durante sua existência, de 1933 a 1945, tendo também atuado na criação da Associação Brasileira de Escritores (ABDE), em 1942, da qual foi o presidente da primeira diretoria ${ }^{1}$. Como outros de sua geração, Octávio Tarquínio garantiu

\footnotetext{
${ }^{1}$ A criação da ABDE simbolizou uma das primeiras iniciativas, por parte de alguns intelectuais, de usar o associativismo corporativista, tão em voga na década de 1930, contra os excessos do autoritarismo do Estado Novo. Entre os fundadores figuraram: Octávio Tarquínio de Sousa, Sérgio Buarque de Holanda, Astrojildo Pereira, Graciliano Ramos, José Lins do Rego, Sérgio Milliet, Mário Neme, Mário de Andrade, Oswald de Andrade, Abguar Bastos, Lourival Machado, Paulo Emílio Sales Gomes, Antônio Cândido Melo e Souza, Dionélio Machado, Érico Veríssimo, Reinaldo Moura e Raul Riff. O nome da nova agremiação profissional, associado ao conjunto de seus primeiros organizadores, imputava ao substantivo escritores uma designação adequada aos valores da época, posto que, abarcava todos os que procuravam viver da palavra escrita, nas suas variadas materializações: o romance, o ensaio sociológico, a crítica literária, a biografia, a poesia, a história. Entre algumas das iniciativas da ABDE, destacaram-se, no campo das reivindicações profissionais, a elaboração do projeto de reconhecimento e regulamentação dos direitos
} 
o sustento material realizando carreira profissional na burocracia do Estado. Tornou-se, em 1932, um dos ministros do Tribunal de Contas da União, aposentando-se das funções que desempenhara nesse órgão público, em 1946.

Nosso objetivo, nesse artigo, é analisar a maneira peculiar de relacionar narrativa biográfica à escrita da história, na forma como esta veio a se manifestar nos textos assinados por Octávio Tarquínio. Mais do que uma caracterização da identidade maior da obra desse autor, buscaremos, nesse artigo, situar, de forma sintética, alguns dos valores e concepções que informaram a discussão sobre os usos e pertinências da biografia entre as narrativas de natureza historiográfica, no curso do tempo em que o autor constituiu grande parte de sua produção - décadas de 1930 a 1950.

Em nossas investigações, as biografias históricas assinadas por Octávio Tarquínio de Sousa materializaram um cruzamento deveras interessante, a saber: (i) a proposta de contribuir, como outros contemporâneos, para a elaboração de interpretações históricas que se queriam inovadoras, mesmo que dialogando com tradições historiográficas consagradas; (ii) o projeto de testar e aprofundar os usos da biografia como narrativa que explicitasse as relações entre indivíduo e sociedade, com destaque para as experiências de configuração da entidade nacional.

Esse cruzamento individualizou a produção letrada de Octávio Tarquínio frente a de outros parceiros e amigos de sua contemporaneidade - Gilberto Freyre, Caio Prado Júnior, Sérgio Buarque de Holanda - que, cumpre lembrar, cada qual à sua maneira, também lançaram-se em redescobrimentos e reinvenções da História do Brasil, nas suas diversas possibilidades. As biografias históricas assinadas por Octávio Tarquínio foram todas publicadas em coleções relacionadas ao campo dos Estudos Brasileiros ${ }^{2}$, inserindo-se,

autorais, encaminhado à Assembléia Nacional Constituinte, em 1946, e, no campo de um certo ativismo político, a realização do I Congresso Brasileiro de Escritores, em janeiro de 1945, em São Paulo. Em especial, esse congresso, pelas suas dimensões e desdobramentos, representou uma das manifestações do processo de redemocratização que então se iniciara (Abreu 2001: 1535-6).

${ }^{2}$ À exceção de Evaristo da Veiga, publicado em 1939 na Coleção Brasiliana, pela Companhia Editora Nacional, todos as outras primeiras edições das biografias assinadas por Octávio Tarquínio de Sousa fizeram parte da Coleção Documentos Brasileiros, pertencente a José Olympio. 
como tantos outros textos, nos esforços analíticos de decifração, por vezes de monumentalização, do caráter nacional brasileiro.

Tarquínio de Sousa compreendeu o uso da biografia na escrita da história política nacional como fórmula testada com sucesso e exemplaridade por Joaquim Nabuco - Um Estadista do Império - e por Oliveira Lima - D. João VI no Brasil. Quis, num certo sentido, dar continuidade a essa maneira peculiar de escrever história, produzindo biografias em consonância com os ventos de renovação que o gênero veio a sofrer, durante a década de 1920. Houve, nesse sentido, uma moderna tradição a informar duplamente, e em estreita correspondência, a escrita de biografias e a produção historiográfica de Octávio Tarquínio de Sousa.

\section{Biografias modernas}

$\mathrm{Na}$ introdução de seus ensaios sobre o desenvolvimento da biografia na Grécia antiga, Arnaldo Momigliano elaborou algumas rápidas considerações sobre o que ele denominou de papel ambíguo da biografia entre as pesquisas históricas. A referida ambigüidade estaria associada à questão de que a biografia tanto poderia ser uma ferramenta quanto uma fuga das investigações sociais. A discussão justificava a relevância do assunto tratado em seus ensaios: a história da biografia e de suas relações com a historiografia, no universo de seus inventores - os gregos antigos (Momigliano 1993: 1-7).

As análises de Momigliano sobre o desenvolvimento da biografia entre os gregos foram publicadas em 1971, e corresponderam a conferências proferidas na Universidade de Harvard, em 1968. Inventariando polêmicas acerca das fronteiras e interseções entre a biografia e a história, Momigliano concluía que, no momento em que realizou suas conferências, poucos duvidavam de que a biografia fosse um tipo de história, o que, na época, finais da década de 1960, numa certa medida, parecia ser um tanto paradoxal, se comparado às controvérsias que agitaram a discussão sobre competências e campos do fazer biográfico e do fazer historiográfico, nas décadas iniciais do século XX.

Nesse período, segundo Momigliano, a distinção entre história e biografia, numa certa leitura, atribuída às obras de Políbio e também de Plutarco, estava sendo negada por turbulentos clamores internacionais, protagonizados, entre outros, na Alemanha, por Emil Ludwig (1881-1948), na França, por André Maurois (1885-1967) e, na Inglaterra, pelo polêmico Lytton Strachey (1880- 
1932). O debate teria adquirido proporções maiores e assumido a forma da proposta de caracterizar o que foi denominado de biografia moderna ${ }^{3}$.

As discussões sobre a emergência de uma biografia moderna ganharam corpo, no cenário europeu, no momento imediato ao fim da $1^{\text {a }}$ Grande Guerra. Uma geração de escritores, nascida nos anos oitenta do século XIX, lançados como intelectuais sob os ventos da Belle Époque, jovens em plena atividade literária quando o confronto militar exacerbou seus horrores e idiossincrasias, encontraram na escrita de biografias uma das trincheiras de defesa da autonomia do sujeito individual. Perante a avalanche de mudanças sociais e políticas no Velho Mundo, aspiraram rever o conceito de natureza humana, a partir de uma crítica às concepções racionalistas e cientificistas, tão caras para as ambiências intelectuais dos oitocentos, em comunidades européias.

Segundo Stuart Hughes, entre 1890 e 1914, uma gama variada de pensadores - Bergson, Freud, Weber, Croce, Dilthey, entre outros -, empreenderam, cada um à sua maneira, em seus respectivos campos de atuação - a filosofia, a psicologia, a sociologia, a história -, reflexões sobre o homem e sobre os saberes que se dispunham a conhecê-lo, realizando o que Hugues categorizou como uma revolta anti-positivista. Esta, por seu turno, manifestou-se por intermédio da defesa de uma concepção de natureza humana mediada pelo conceito de inconsciente, pela valorização do meio histórico e cultural na compreensão das possibilidades e limites da ação dos indivíduos no mundo, pela junção, em escalas diferenciadas, do intuitivo e do racional nos métodos cognitivos, por fim, pela afirmação do caráter imanente de tudo o que dissesse respeito ao homem e aos saberes que buscassem decifrá-lo (Hughes 1977: 33-66).

Tais discussões, na verdade, teriam composto um dos capítulos da emergência de uma sensibilidade moderna, com direito a todas as ambigüidades que a mesma trouxe em termos da proposição do novo nos diversos campos das realizações humanas. Teriam igualmente e, numa certa medida, representado, de forma aguda, a crise de valores éticos, estéticos e políticos que

\footnotetext{
${ }^{3}$ Entre os textos que tematizaram a discussão sobre a biografia moderna destaque deve ser conferido ao livro de Daniel Mandélenat - La biographie, Paris: PUF, 1984 -, o qual, ao analisar a história da biografia, distinguiu e caracterizou três paradigmas: a biografia clássica, a biografia romântica e a biografia moderna. Essa última, em particular, foi associada ao relativismo ético, à psicanálise e às transformações da epistemologia histórica, no alvorecer do século XX.
} 
afligiu o cenário europeu, em finais do século XIX (Everdell 2000). O gênero biográfico não escapou de um redimensionamento de seus significados e de suas metodologias de produção, relacionados, desde então, à emergência de uma sensibilidade moderna.

André Maurois, Emil Ludwig e Lytton Strachey tornaram-se os autores emblemáticos de biografias onde homens e mulheres desciam de seus panteões de notáveis para personificar a grandeza e a miséria de suas condições humanas. Cada um desses autores, donos de estilos próprios e diferenciados, representaram, com direito a polêmicas, os arautos de uma escrita biográfica que se queria moderna (Cavalheiro 1943). Todos, em seus países de origem, e nas traduções de suas principais obras, alcançaram sucesso editorial e reconhecimento internacional como renovadores e atualizadores de um gênero que, segundo alguns, no decorrer do século XIX, havia sido engolfado pelos panegíricos oficiais de memórias nacionalistas.

Antes de qualquer teorização e/ou categorização mais sistemática acerca das biografias modernas, houve toda uma proliferação de textos, ainda ancorados no oportunismo do sucesso editorial que as narrativas de vida de famosos pudessem

134 vir a desfrutar. Tais textos ensaiaram o abandono das monumentalizações ufanistas de escritores e dirigentes políticos, apostando na boa receptividade do esquadrinhamento da humanidade contraditória de todo e qualquer sujeito individual. Nesse ponto, a atmosfera eufórica da Belle Époque, na sua modernidade de crescimentos urbanos e anonimatos providenciais de multidões, pareceu ter sido mais um ingrediente favorável à proliferação de leitores ávidos pelas mesquinharias pessoais de ilustres personagens. Caso fosse bem escrita, em prosa fluente e bem encadeada, a narrativa biográfica figuraria como o romance da vida de homens de carne e osso. Uma espécie de folhetim reeditado e em diálogo com o dilaceramento realista e triunfante de toda e qualquer subjetividade humana.

Os textos de Lytton Strachey assumiram, nesse contexto, caráter paradigmático. Tornaram-se não só o modelo de escrita biográfica inovadora, mas, em especial, do uso do humor fino, bem dosado, quanto às imagens em letras de seus biografados. Arnaldo Momigliano, entre outras observações sobre esse autor, destacou a cena na qual Bertrand Russell havia sido flagrado em risos ao ler Eminent Victorians (Momigliano 1993: 3). Publicado em 1918, o referido texto foi o principal responsável pela notoriedade e pelo sucesso editorial do escritor inglês, de fato, plenamente consagrado com o surgimento de sua biografia sobre a Rainha Vitória, em 1921. A projeção de Lytton Strachey, somada em particular, a de sua amiga pessoal, Virgínia Woolf, firmaram o 
grupo de Bloomsbury como uma referência no cenário intelectual europeu da época. Para a produção literária em língua inglesa, o Bloomsbury Group passou a significar uma crítica aguçada contra os valores culturais associados à Inglaterra vitoriana ${ }^{4}$.

Foi, contudo, André Maurois quem, a princípio, buscou delimitar os parâmetros de uma nova escrita biográfica. Em 1928, o autor sistematizou idéias, em publicação que reuniu conferências proferidas no Trinity College, em Cambridge, local onde Strachey havia estudado, sob o título de Aspectos da Biografia. André Maurois se dispôs a fazer uma espécie de radiografia do estado atual das questões sobre narrativas de trajetórias individuais, desfiando os seguintes temas: a biografia moderna, a biografia como obra de arte, a biografia considerada como ciência, a biografia como um meio de expressão, a autobiografia e as relações entre a biografia e o romance (Maurois 1929).

Usando exemplos da literatura inglesa, o autor francês identificava na obra de Lytton Strachey um divisor de águas, uma reação contra os tediosos e volumosos panegíricos que tipificaram biografias do período vitoriano. A despeito do impacto causado pelos posicionamentos de Strachey, em 1918, Maurois avaliava que, em 1928, os críticos não haviam de todo desqualificado as biografias vitorianas. De qualquer forma, para o autor, a obra de Strachey havia inaugurado uma nova escrita biográfica, elevando-a à categoria de obra de arte. Strachey teria personificado, magistralmente, o historiador que, ao transformar o material pesquisado em texto, desempenhou também funções de artista, somando precisão à fluidez e à beleza da narrativa, decifrando e humanizando seus notáveis personagens (Maurois 1929: 7-9).

As mudanças na forma do texto biográfico e na figuração do sujeito biografado foram os principais indicativos para a confirmação de que uma nova biografia estava a surgir. Nos argumentos de Maurois, a emergência dessa nova biografia remontava ao alvorecer do século XX. Esse tempo, segundo o autor francês, teria sido um período de revolução intelectual, marcado, entre outros aspectos,

\footnotetext{
${ }^{4}$ A residência dos Strachey foi um dos pontos de encontro do grupo de Bloomsbury. O nome de um bairro londrino tornou-se a designação de um conjunto de amigos que estudaram em Cambridge, no Trinity ou no King's College, compondo um círculo de escritores, intelectuais e artistas, do qual participaram Leonard e Virgínia Woolf, Arthur Valley, Clive e Vanessa Bell, irmã de Virgínia, Roger Fry, John Maynard Keynes, entre outros (Strachey 2001: 9-21).
} 
pela crescente interferência da psicologia e da ética nos métodos de aprendizagem e investigação. Uma certa liberdade na formulação de inquéritos afetou, sobremaneira, aos romancistas, espirrando sobre o conhecimento histórico e, principalmente, sobre uma de suas manifestações, a biografia. O biógrafo moderno, em diálogo com essas mudanças, seria aquele que entenderia o biografado como uma verdade a ser construída a partir de um método de investigação pautado no abandono de quaisquer idéias pré-concebidas e no levantamento e na análise de toda documentação disponível (Maurois 1929: 13-15).

Entre os aspectos marcantes das biografias modernas, André Maurois destacou, primeiramente, o que nas suas palavras seria a procura corajosa pela verdade (Maurois 1929: 19-24), temperada por um aguçado senso de percepção da complexidade e da mobilidade dos seres humanos e, em menor escala, por um senso de unidade de sua natureza.

Para explicar tais percepções, o autor francês mencionou a importância da filosofia de Bergson e de seus seguidores. Situou-os ao lado dos progressos da física e da biologia que, por caminhos diversos, desconstruíram teorias baseadas na indivisibilidade do átomo e da célula. A psicologia, com seus estu-

136 dos acerca da imutabilidade dos comportamentos humanos, também interferiu na crescente alusão às imprevisibilidades das ações humanas, o que, em parte, foi ainda reavaliado pelo sistema freudiano e pelas discussões sobre o conceito de inconsciente. Mesmo tendo senões ao uso deveras alargado dessa noção, o que para Maurois teria abalado o valor na crença da liberdade humana, o autor forçosamente reconhecia sua validade na constatação hodierna da complexidade das ações humanas.

Comparando átomos a indivíduos, Maurois entendia o caráter de cada um como um conjunto de diversas personalidades e denunciava a ilusão de alguns em querer apreender a "real self". Para ele a máscara funcionaria como a melhor chave de compreensão para as contradições e multiplicidades das vivências individuais. O homem moderno seria aquele que acreditaria na dependência direta entre a análise da psique humana e o exame das diversas facetas e dos pequenos detalhes comportamentais.

Os biógrafos modernos, e Maurois entre eles se enquadrava, teriam ecoado os efeitos dessas concepções numa maneira própria de retratar seus biografados, não os representando como massas sólidas de vícios e virtudes, evitando julgamentos morais e percebendo que ninguém se mantinha o mesmo entre a maturidade e a velhice (Maurois 1929: 27-30). Relativizando seus próprios juízos, André Maurois asseverava que a perspectiva de reconhecer a 
complexidade da personalidade humana era algo submetido aos ritmos e valores de cada época. No momento particular em que ele proferia suas conferências, a afirmação dessa complexidade era, no seu entender, dominante e isso deveria ser compreendido como uma segunda característica da modernidade que também afetava a escrita de biografias.

Como terceira e última característica das biografias modernas, André Maurois apresentou a adequação desses textos àquilo que os leitores de sua época procuravam encontrar em narrativas sobre vidas alheias. Para o autor, o homem moderno seria mais inquieto e instintivo; um assombrado por seus hábitos de auto-análise que procuraria, na leitura de um texto ficcional ou de um texto histórico, encontrar irmãos que partilhassem seus problemas. Nesses termos, o prognóstico de Maurois pintava o quadro de uma era das incertezas, onde homens desassossegados poderiam vislumbrar nas biografias uma espécie de pedagogia existencial: o aprendizado com as falhas e dúvidas dos grandes homens (Maurois 1929: 34-35).

Caberia destacar, nessas apreciações de Maurois, o quanto elas traduziram uma perspectiva imanente de compreensão do indivíduo, tomado como sujeito humano ligado à vida, à sua duração e às suas contingências. $\mathrm{O}$ autor francês posicionava-se ao lado de outros contemporâneos que negaram o transcendente como campo possível de conhecimento no que dizia respeito à condição humana. As considerações de Maurois, nesse sentido, exemplificavam um lugar de fala, no universo da crise de valores éticos e políticos de sua época. A biografia moderna funcionaria como instrumento para compreender e, em certa medida, julgar as ações dos indivíduos na história, auxiliando os homens perplexos do alvorecer do século XX. Nesse ponto repousava a dimensão ética da biografia na sua versão moderna.

As três características essenciais da biografia moderna nomeadas por Andre Maurois - a procura corajosa da verdade, a valorização da complexidade humana, a busca de homens modernos por textos e personagens "à sua imagem e semelhança" - tornavam o trabalho de elaboração dessas novas narrativas de vida uma empreitada dificultada por alguns impasses. O principal deles referia-se à conciliação de duas demandas aparentemente antagônicas: a investigação da verdade histórica e a pesquisa das expressões de uma personalidade.

Para Maurois, nos quadros de sua época, a primeira esteve, fundamentalmente, associada aos trabalhos de scholars, e a segunda manifestou-se nas obras dos artistas. Haveria conciliação possível? André Maurois acreditava ser possível mesclar a insistência na verdade com o desejo de beleza e se pro- 
punha a discutir a biografia como uma obra de arte e a biografia considerada como ciência. Esperava, com isso, mostrar que arte e ciência poderiam ser reconciliadas e que, um livro científico, perfeitamente construído, seria um trabalho de arte (Maurois 1929: 37-38).

Ao discutir a biografia como arte e como ciência, André Maurois, sem intenções totalmente declaradas, apresentou caminhos e estratégias para a produção de um texto biográfico que cumprisse, de forma exemplar, a conciliação entre a verdade e a beleza. Para além do diagnóstico acerca do que caracterizava as biografias modernas, Maurois esboçou uma metodologia do como proceder para produzi-las, desdobrando seus argumentos em prognósticos avaliativos sobre as relações entre história, ciência e literatura.

Nas suas considerações acerca da dimensão artística dos textos biográficos, André Maurois enfatizou o esforço de criação e montagem realizado pelo biógrafo ao circunscrever, sob a forma da narrativa verossímil, a trajetória de vida de seu biografado. Se o biógrafo, diferentemente do romancista, não realizava, na plenitude de suas potencialidades, a invenção de personagens; se o biógrafo enfrentava limitações impostas pelo fato de que protagonistas e antagonistas 138 de sua história tiveram existências mundanas e reais, tais balizas não o impediam de praticar o exercício de uma determinada estética ao dar forma e enredo às vivências e dramas pessoais de seus escolhidos.

Como o pintor de paisagens ou de retratos, o biógrafo deveria selecionar as características essenciais do que ele estivesse contemplando. Por intermédio dessas escolhas, caso ele conseguisse fazê-las sem comprometer a retratação do todo, o biógrafo estaria protagonizando a função do artista (Maurois 1929: 50). Nesses termos, uma característica fundamental da arte de escrever biografias modernas seria o cuidado com a seleção dos detalhes. Nessa discussão, Maurois estabeleceu diferenças entre os ofícios do biógrafo e do historiador. Para ele, um scholar, nos seus procedimentos de pesquisa, acumulava um grande número de informações e as ordenava sem maiores cuidados seletivos. Nem todos, contudo, cometeriam esse pecado, pois haveria alguns que realizavam a seleção do material pesquisado, procurando estabelecer linhas gerais de sistematização e produzindo, assim, algum tipo de obra de arte. O biógrafo, de fato preocupado com a dimensão estética de seu texto, pouparia seus leitores do fardo de informações inúteis.

Seria uma espécie de dever do biógrafo ler tudo o que dissesse respeito à vida do sujeito em estudo, com vistas a não correr o risco de perder ou ignorar detalhes importantes. Para Maurois, todavia, a biografia não deveria consistir 
numa narrativa que pudesse tudo contar. A seleção do detalhe significante e essencial seria parte imprescindível do trabalho do biógrafo. Ao descartar o desnecessário, o biógrafo melhor destacaria os aspectos que vivificassem o biografado, na maneira como esse se comportou em seu tempo de vida. Nesse ponto repousaria uma tarefa difícil: fazer os leitores encontrarem seres de carne e osso por trás das nuvens de papel, dos discursos e das ações do biografado (Maurois 1929: 62-64).

André Maurois afirmava que a ciência histórica deixava os leitores na incerteza quanto às individualidades e, caso essas viessem a ser tratadas, cumpririam a função de causas potenciais na ordenação dos eventos. A arte seria o oposto da generalização, ela descreveria apenas o individual e desejaria o que fosse único. Não poderia haver ciência para as idiossincrasias do caráter. Um livro que descrevesse um homem em todas as suas inconsistências seria uma obra de arte (Maurois 1929: 64-66).

$\mathrm{Na}$ análise do tema da biografia considerada como uma ciência, as argumentações de André Maurois divagaram sobre as relações entre a escrita da vida de um eleito e o grau de verdade histórica que ali poderia existir. Suas análises partiram de algumas questões, a saber: haveria na biografia uma verdade científica? Seria possível conhecer a verdade sobre um homem? Em que extensão poderíamos descobrir a verdade sobre um tempo ou sobre um período, a partir do registro da história de um homem?

Ciente do perigo e do absurdo de tentar estabelecer um paralelismo estreito entre as ciências da natureza e as ciências humanas, Maurois se dispôs a responder tais questões com extrema cautela, debitando, em particular, da conta dos procedimentos metodológicos que interferiam na produção da narrativa "biográfica" "o ônus" de algumas de suas limitações. Haveria assim como conhecer a verdade sobre um homem? Para Maurois, não. O biógrafo deveria tentar fixar a mutabilidade de luzes e sombras, ou tentar produzir o som da autêntica nota individual. O que viesse a alcançar, contudo, seria um tipo de verdade totalmente diferente daquela perseguida pelo químico ou pelo físico (Maurois 1929: 103).

As maiores digressões de Maurois foram deixadas para uma derradeira questão, qual seja: em que grau seria possível estudar uma época da história por intermédio da escrita da vida de um homem. E mais, em que proporções seria lícito fazer de um homem a figura central de uma época. Segundo André Maurois, o biógrafo poderia transformar um indivíduo numa figura central e fazer com que os acontecimentos de uma época começassem e terminassem 
na vida do protagonista eleito. Considerando a biografia como uma obra histórica, Maurois, contudo, buscava frisar suas identidades modernas.

O biógrafo deveria atentar para as especificidades de sua narrativa frente ao que cabia ao campo das produções historiográficas. Se a biografia de um eleito fazia parte da história, ela não poderia responder por toda a história; da mesma forma que essa última não deveria ser entendida como um mero somatório de relatos biográficos. Haveria diferenças entre os objetivos da biografia e da história. A primeira, acima de tudo, seria o relato da evolução da vida de um homem. A história deveria ser para esse protagonista aquilo que o pano de fundo representaria para o pintor de retratos (Maurois 1929: 107-110).

A metáfora do pintor de retratos como simbologia para o trabalho do biógrafo, nas suas relações com a história, veio também a ser utilizada, como conclusão final de Maurois, acerca das possibilidades da biografia ser considerada uma ciência. $\mathrm{O}$ pintor de retratos, como o biógrafo, deveria dominar as técnicas de seu ofício. Todavia, diferentemente do homem de ciência, preocupado com explicações gerais, pintores e biógrafos objetivariam retratar o que fosse único e individual, e nisso um trabalho de natureza distinta da ciência. Uma citação de Lytton Strachey socorreu Maurois

140 na finalização de seus argumentos, desta feita para insinuar algo que o autor francês não ousou afirmar tão categoricamente quanto seu mestre britânico:

(...) É óbvio que a História não é uma ciência; é óbvio que a História não é uma acumulação de fatos, mas a relação entre eles (...) Fatos relacionados ao passado, se forem coletados sem arte, serão compilações, e compilações, sem dúvida, podem ser úteis, mas elas não são História, tanto quanto manteiga, ovos, sal e temperos não são uma omelete. (Maurois 1929: 110-111)

Importante perceber, nessas formulações conclusivas de Maurois, a tônica na singularidade, no único, no individual e no irrepetível como mote diferenciador dos saberes sobre as experiências humanas. Nesse enfoque, a biografia poderia figurar como a melhor expressão de um conhecimento histórico, visto como manancial de circunscrição do singular. Concebido dessa forma, contudo, o saber histórico não poderia ser considerado uma ciência, caso essa última viesse a ser conceituada como conhecimento racional, formulador de leis explicativas ou de análises centradas na causalidade de fenômenos numa ordem geral.

Maurois, como outros intelectuais de sua época, e, nesse aspecto, exemplificando uma sensibilidade moderna, criticou os valores de uma racionalidade 
científica ancorada no percurso teórico e metodológico das ditas ciências da natureza, tomadas por alguns, entre esses os positivistas, como o modelo a ser seguido por todos os que desejassem produzir saberes verdadeiros. O conhecimento do mundo dos homens exigiria para além da técnica, uma boa dose de intuição, uma poiesis, e nisso a arte de criar algo, em especial, uma compreensão que informasse e sensibilizasse. A história, na forma do que Strachey denominou de compilações, informaria, mas não sensibilizaria. Para Strachey e Maurois, a história como saber sobre a vida dos homens não poderia inserir-se no paradigma de ciência então em voga, tanto quanto, a despeito das diferenças, a biografia também não poderia. Na discussão sobre as relações entre biografia e história, o que estava em pauta era o próprio valor do conhecimento histórico, a partir do questionamento de sua natureza epistemológica.

Se a biografia, nas suas relações com a história, em muitos aspectos deveria ser entendida como um obra de arte, as argumentações de André Maurois, nesse ponto, vieram a ser desdobradas em aspectos sobre os usos da narrativa biográfica. A partir de uma introdutória ponderação acerca das funções da arte como veículo para os sentimentos e percepções do artista, Maurois apresentava a seguinte questão: seria a biografia, tanto quanto o romance e a autobiografia um meio de expressão, em especial dos pontos de vista e das emoções do biógrafo?

Desta feita, mais do que em outros momentos de suas argumentações, o autor francês utilizou-se de sua própria experiência como biógrafo para tentar responder à questão proposta. André Maurois confessava que suas escolhas de sujeitos a serem biografados estiveram diretamente vinculadas à identificação de idéias e valores com os quais simpatizava. Firmando uma posição polêmica, Maurois asseverava a pertinência da biografia como meio de expressão, particularmente quando o biógrafo entendesse seu biografado como o outro que pudesse aplacar secretas necessidades de sua própria natureza. Nessa maneira, os sentimentos e as aventuras do biografado seriam uma mediação para os sentimentos do biógrafo e, numa certa extensão, a narrativa tornar-se-ia uma espécie de autobiografia disfarçada de biografia (Maurois 1929: 125).

Se tais estratégias seriam comuns e possíveis, Maurois não perdia de vista a questão da legitimidade da escrita biográfica, ameaçada por práticas onde a busca de si pudesse vir a suplantar o retrato do outro. Nesses casos, o biógrafo correria o risco de, inconscientemente, deformar a verdade histórica, o que abriria espaços para a condenação da qualidade de seu trabalho, em função de uma excessiva subjetividade. Para André Maurois, antes de qualquer outro aspecto, a história, ou aquilo que soubéssemos sobre ela, deveria ser respeitada. 
Publicar uma biografia, ou anunciá-la como tal e não como um romance, seria o anúncio de fatos autênticos, aliás a moeda de troca e de confiabilidade entre o biógrafo e seus leitores. O biógrafo, nesse sentido, deveria ao máximo procurar ser fiel àquilo que o biografado de fato vivenciou e sentiu no curso de sua existência (Maurois 1929: 131-132).

Conclamando a fala hipotética de um historiador, Maurois alertava para os problemas do método biográfico; problemas associados ao infinito cuidado, à absoluta honestidade, à fixação de nunca alterar fatos singulares. Ciente dessas limitações, e posando de biógrafo crítico de si mesmo, Maurois asseverava uma espécie de tautologia: a despeito de todos os problemas, não haveria outro método. Se o fato científico poderia vir a ser explicado por procedimentos de análise e de síntese, o entendimento de um ser humano e de sua inevitável complexidade não poderia ser resumido a uma exaustiva compilação de detalhes (Maurois 1929: 133).

Se o biógrafo, entre dificuldades, cuidados e hesitações, poderia fazer da biografia um meio de expressão, em uma dimensão diferenciada, o mesmo teria valor para os leitores dessas narrativas de vida. Como textos dessa natureza, com a pretensão de alcançar o realismo, as biografias poderiam guardar, em suas páginas, exem-

142 plos comportamentais para leitores ávidos pelas existências alheias.

A recepção e as apropriações do texto biográfico pelos leitores ditavam, por sua vez, as possibilidades de uso pedagógico e moral dessas narrativas de vida. Se isso denotava um valor de uso para as biografias, em especial daquelas cujos protagonistas já fossem considerados notáveis, incorria, paralelamente, em mais uma responsabilidade por parte do biógrafo na realização de seu ofício. Maurois finalizava suas considerações sobre a biografia como meio de expressão, alertando para a prudência em não fazer da narrativa de vida de um homem um repositório de moralismos, que, à sua maneira, poderiam também representar, excesso de subjetividade por parte das impressões do biógrafo.

As últimas considerações de André Maurois dedicaram-se, respectivamente, à autobiografia e às relações entre biografia e romance. Retomando questões discutidas anteriormente, em particular as que versaram sobre as possibilidades e limites de conhecer a verdade sobre um homem, o autor francês acrescentou mais algumas inferências sobre o fazer biográfico.

Entendendo a autobiografia como uma derivação da biografia, André Maurois encontrava, nas particularidades dos métodos autobiográficos, argumentos preciosos sobre as limitações intrínsecas ao conhecimento da verdade acerca da vida de um homem. Haveria uma espécie de ilusão autobiográfica a ser lembrada, nos termos de que nenhum homem guardava lembranças 
completas sobre suas experiências, sentimentos, pensamentos, sonhos e racionalizações. Memórias seletivas e imperfeitas, formadas por muitos esquecimentos, voluntários e involuntários, consistiriam na matéria bruta a partir da qual uma narrativa existencial poderia ser produzida. Nenhum homem, de fato, era senhor de si e isso se tornava contundente e trágico quando alguém decidia narrar sua vida de forma ordenada e significativa. Debitando da conta da complexidade da psique humana os dividendos dessas limitações, Maurois concluía que o autor de uma autobiografia ideal ainda estaria por nascer ${ }^{5}$.

Sua última reflexão correspondeu a uma análise acerca das dificuldades de se alcançar a verdade sobre a vida de um homem, a partir de uma comparação entre a liberdade de criação do romancista e as imposições da fundamentação documental, típicas do ofício do biógrafo. Se na construção de seus personagens, o romancista poderia e deveria lançar mão das imagens necessárias, no sentido de dar-lhes vida, percepções, pensamentos, ação; o biógrafo, tanto quanto o historiador, assim não poderia proceder, tendo que circunscrever suas inferências àquilo que estivesse presente nos vestígios documentais referentes ao seu biografado.

A diferença fundadora entre a narrativa ficcional e a de caráter realista, em muitos aspectos, possibilitava ao romancista, especialmente àquele, em alguma medida, ancorado na perspectiva de criar textos e personagens verossímeis, a produção de relatos muito mais convincentes na sensibilização de leitores em busca de boas histórias sobre misérias e grandezas humanas. Essa constatação foi encaminhada para uma derradeira questão: em que medida, o biógrafo poderia valer-se das técnicas do romancista?

Para Maurois, a busca, por parte dos biógrafos, da elaboração de narrativas humanizadoras de seus biografados, dificultaria ainda mais suas tarefas sempre norteadas pela fronteira dos registros documentais. Nessa aparente adversidade, contudo, Maurois visualizava um desafio e um estímulo, suportado e, sem dúvida bem realizado, pelos biógrafos que criaram belos retratos em papel e letras.

Em certa medida, os bons biógrafos conseguiriam, como os bons romancistas, manter Sherazade viva, caso ela fosse narrar suas histórias entre seus

\footnotetext{
${ }^{5}$ A despeito do ceticismo, ou de sua maneira muito peculiar de caracterizar a natureza humana - o ser complexo, em constante mudança, escravo da transitoriedade do tempo - André Maurois finalizou sua conferência sobre autobiografia enumerando e comentando textos qualificados como satisfatórios, na qualidade de trabalhos autobiográficos.
} 
contos das mil e uma noites. Para que a vida de Sherazade viesse a ser poupada, a história que estivesse a narrar, sendo a de um único homem, suas desventuras e esperanças, deveria primar pela cadência envolvente e provocativa da curiosidade sobre o desenrolar da trama, já que o final - a morte do biografado -, a princípio, seria esperado (Maurois 1929: 137-138).

Para Maurois, a sobrevivência de Sherazade dependeria, em larga medida, do sujeito biografado, não só pelas especificidades de sua trajetória de vida, como também, pela forma como essas viessem a ser sistematizados pelo biógrafo. Seria, nesse ponto, fundamental fazer do biografado o Homo Biographicus, uma terceira categoria diferente do Homo Sapiens e do Homo Fictus. À sua maneira, abusando de imagens irônicas, André Maurois concebia cada um desses como espécimes habitantes de mundos correlatos, porém diferentes: a vida real, o espaço ficcional e o universo particular da narrativa biográfica. $\mathrm{O}$ autor francês afirmava sua concepção acerca da biografia: o produto resultante da difícil junção entre técnica e intuição. Estava, sem dúvida, a dignificar o gênero biográfico e mais, a valorizar uma certa maneira de escrever biografias, onde aliás, ele próprio figurava como entusiasta e divulgador (Maurois 1929: 199-203).

\section{Em busca de homens históricos}

As indagações de Maurois, no momento de sua emergência, tornaram-se uma matriz importante de idéias sistematizadas acerca dos usos, valores e características do gênero biográfico. Proferidas em inglês, publicadas em francês, traduzidas para o inglês, entre 1928 e 1929, as lectures de Maurois circularam nas prateleiras de livros de intelectuais de outras terras e línguas, aportando em solo brasileiro, para a alegria ingênua dos bacharéis que liam avidamente tudo que da França brotasse.

A apropriação desse debate animou letrados brasileiros a desejar que, também no campo das narrativas de vida - biografias, memórias, autobiografias - viéssemos a superar o "atraso" frente às últimas inovações européias. Interessante constatar que o debate sobre a renovação do gênero biográfico ocorreu em paralelo e, em relação direta, ao crescimento da publicação de histórias de vidas individuais. Na leitura de Alceu Amoroso Lima assistiu-se a uma verdadeira epidemia biográfica (Lima 1931: 165-177). Mais do que um mero fenômeno quantitativo, a epidemia biográfica existiu como tema propulsor, caro a muitos dos que se dedicaram à critica literária na época, e que, no exercício dessa atividade intelectual, estabeleceram as dimensões e significados da dita biografia moderna no conjunto da produção bibliográfica brasileira. 
Não pretendendo esgotar, nos limites desse artigo, as polêmicas que mobilizaram letrados nos seus diagnósticos sobre a epidemia biográfica, cumpre destacar uma de suas apropriações. Entre o final da década de 1920 e a de 1950, com destaque para os anos trinta e os anos quarenta, intelectuais empenhados na renovação da literatura e da história nacional, dispostos a circunscrever o campo dos Estudos Brasileiros, compreenderam a renovação da biografia como mais um aspecto necessário entre as estratégias de atualizar análises sobre a realidade nacional. No diálogo com as lições dos mestres da biografia moderna, em especial Lytton Strachey e André Maurois, alguns letrados brasileiros acharam que vultos eminentes da história política e da produção literária brasileira poderiam ter suas vidas apresentadas como trajetórias de homens de carne e osso, a sofrer todas as mazelas da condição humana - criadores e criaturas de experiências e enredos históricos.

O fazer biográfico, sob a clave de uma narrativa humanizadora de seus protagonistas, poderia tornar-se uma pedagogia de vida a instruir leitores no catecismo dos saberes sobre a nação brasileira. De forma resumida, diríamos que essa perspectiva informou - tanto quanto veio a ser informada por ela - a produção das biografias históricas que compuseram a obra de Octávio Tarquínio de Sousa.

Assim, para Octávio Tarquínio de Sousa, a reinvenção da história brasileira, proposição candente entre os que respiraram a atmosfera das interrogações modernistas (Saliba 2000: 43-49), seria promovida, naquilo que se referia especificamente ao processo de constituição do Estado Nacional, por intermédio de um fazer biográfico que procuraria compreender as ações dos homens, suas virtudes, defeitos e hesitações, no seu meio social e histórico, ou como Tarquínio de Sousa costumava nomear, no espírito de sua época.

Esse autor, ao desenhar a fisionomia de seus biografados, em retratos de papel e letras, perseguiu, em igual proporcionalidade, a compreensão do período histórico que seus protagonistas viveram. A biografia, como a narrativa da vida de um eleito, tornava-se, então, um instrumento mediador, a via de acesso a uma outra época sob a perspectiva de reconstruir o passado pelos olhos de quem o encenou. Nesses termos, a fisionomia do sujeito individual, exterioridade captada por aparências e traços de comportamento porventura registrados, guardava um caráter a ser decifrado. Na composição de ambos, fisionomia e caráter, exterioridade e interioridade, forma e conteúdo, definiu-se a possibilidade de compreender o espírito de um tempo, as concepções e as idéias por meio das quais cada um, à sua maneira, aprendeu a estar no mundo, com 
uma assinatura e um rosto. Construindo biografias, Octávio Tarquínio de Sousa pretendeu escrever história em uma literalidade absoluta, por vezes ingênua, quanto à premissa de atribuir aos anos, e aos homens, uma fisionomia.

Em suas narrativas biográficas publicadas entre 1937 e 1942- Bernardo Pereira de Vasconcelos e seu tempo, Evaristo da Veiga e Diogo Antônio Feijó - Octávio Tarquínio de Sousa não só materializou a perspectiva de escrever biografias históricas, como igualmente idealizou o projeto, posteriormente abandonado, de elaborar uma História das Regências no Brasil. Acreditava que ao escrever biografias, produziria uma outra história sobre o que considerava um dos períodos mais importantes do processo de formação do Estado nacional. Pela clave da humanização de dirigentes que vivenciaram o momento em que a nação quase não se constituiu como unidade política, Octávio Tarquínio visualizou o cruzamento entre identidades individuais e individualidades históricas.

Na primeira edição da biografia de Diogo Antônio Feijó, diferentemente das que a precederam, consta um prefácio onde o autor dispôs-se a esclarecer suas concepções sobre o fazer biográfico. A impressão de leitura dessas páginas introdutórias nos levou a crer que Octávio Tarquínio, naquela altura de sua

146 trajetória intelectual, podia já demonstrar conhecimento adquirido na escrita de um gênero cada vez mais presente na produção letrada nacional. Falava o biógrafo, a esclarecer e dignificar funções e idiossincrasias de suas escolhas autorais como historiador.

Apresentando seu principal personagem e o tema do qual tratava o novo livro - a vida de Feijó -, o autor, de antemão, ponderava que a notoriedade histórica em torno do protagonista mais do que facilitar, dificultara a realização de um determinado tipo de biografia. Para o autor, seu biografado teria sido, até então, representado pelos olhos deslumbrados de panegiristas ou avaliado com rancor e má vontade por inimigos póstumos ou contemporâneos. Urgia pois realizar o retrato fidedigno do padre paulista, criatura capaz de furor e de ternura, vária, contraditória, complexa. Urgia restituir a Feijó sua condição humana e deslocar imagens que carregaram nas tintas de uma monótona e estúpida coerência. Se Feijó havia sido o homem de governo a serviço da ordem, com senso de autoridade e noção de dignidade, foi também, em outras ocasiões, o político apaixonado e caprichoso, empenhado em ações contraditórias quanto aos princípios que havia encarnado. Desculpando-se junto a biógrafos que poderiam ver em seu texto obra ímpia de dúvida e de negação, Octávio Tarquínio afirmava que o mais importante era descobrir o indivíduo tal como 
ele foi na sua humana realidade, e não como no-lo impingiram apologistas e detratores (Sousa 1942: IX-X).

Octávio Tarquínio ponderou que, mesmo não poupando esforços na pesquisa de todos os elementos e de todo material indispensável à reconstituição da vida de Feijó, desenvolvendo-a com rigor em arquivos e bibliotecas no Rio de Janeiro e em São Paulo, não pretendeu restringir a história, em particular a biografia, ao mero levantamento cronológico ou ao fastidioso relatório tão do gosto de certos caçadores de lêndeas. Reconhecendo que nada seria inútil para o conhecimento de um homem e que as coisas mínimas poderiam por vezes explicar as maiores, Octávio Tarquínio asseverava que não seria apenas por intermédio de uma interminável narração de detalhes que se poderia elaborar uma boa biografia.

Haveria um nível de criação no trabalho do biógrafo, e as conjecturas fariam parte da montagem do texto que pudesse restaurar o tempo que passou. O exercício desse potencial criativo exigiria o máximo de prudência de par com a mais escrupulosa submissão aos fatos na forma como esses se consumaram. Para Octávio Tarquínio, era fundamental atentar para as diferenças entre o trabalho de criação do biógrafo e aquele que seria desenvolvido pelos romancistas. Esses poderiam estabelecer planos próprios e específicos para a duração da vida de seus personagens, aproximando-se em maior ou menor escala do espetáculo do mundo. Historiadores, em especial os biógrafos, deveriam respeitar passivamente o curriculum vitae do biografado (Sousa 1942: X-XI).

Explicitando uma de suas referências autorais, Octávio Tarquínio evocava Lytton Strachey, confessando o quando foi difícil seguir o receituário do mestre. Assim, com adequações, buscou aplicar a máxima de desprezar tudo o que fosse redundante e nada perder do que fosse importante. Nas mudanças no timbre da voz às diferentes fases de vida do biografado, mesmo as mais lentas e monótonas, o biógrafo deveria alcançar o máximo de conformidade com a vida que almejava fixar. Na busca dessa conformidade, entrariam também a sondagem da alma do biografado e o corte em profundidade da época em que a vida transcorreu.

Finalizando a apresentação da biografia de Feijó, Octávio Tarquínio dizia ter se esforçado para permanecer num certo estado de dúvida receptiva com relação ao seu biografado. Adiantava que, por motivos diversos, seu livro, provavelmente, não agradaria aos panegiristas e aos detratores. Esperava, contudo, que os leitores de boa vontade chegassem ao fim do livro com impressão semelhante a sua: uma 
fundada admiração por Feijó, visto embora nas contingências de sua vida e nos limites de suas próprias dimensões (Sousa 1942: XI-XIII).

Como intelectual de seu tempo, a falar a linguagem de sua geração, Octávio Tarquínio tornou-se o autor de biografias históricas em estreito diálogo com o que foi tematizado sobre a emergência de uma biografia moderna. Leitor de Lytton Strachey e de André Maurois, como atestam as marcações nos exemplares de obras desses autores em sua biblioteca, Octávio Tarquínio foi, entre seus contemporâneos, aquele que talvez mais tenha investido na perspectiva de reinventar a história nacional por intermédio da renovação do gênero biográfico.

Ao dar continuidade à prática de escrever a história de momentos ímpares das experiências políticas brasileiras, valendo-se das trajetórias de vida de alguns de seus diletos dirigentes, dialogou, como quis enfatizar, com uma certa tradição, ancorada em referências às obras de Joaquim Nabuco e Oliveira Lima. Ao atualizar a escrita biográfica, inspirando-se nas lições de Lytton Strachey, Octávio Tarquínio imprimiu uma face moderna à sua historiografia, nos quadros dos valores que conceberam as relações entre biografia e história como estratégia eficaz para a informação e a sensibilização de leitores. Nesse

148 cruzamento se manifestou a moderna tradição dos textos de Octávio Tarquínio de Sousa e mais, uma pedagogia dos saberes sobre a nação.

A análise das três biografias publicadas por Octávio Tarquínio de Sousa, entre 1937 e 1942, nos permitiu identificar suas especificidades e, em especial, verificar o quanto cada uma delas fez valer a premissa de que a narrativa biográfica viabilizava, a partir de certos cuidados metodológicos e conceituais, escrever a história de uma época. A época foi o terreno movediço das Regências, utilizando aqui a expressão cunhada por Tarquínio de Sousa, tão expressiva na junção da imagem do terreno que se move, configurando um tempo e uma paisagem histórica a ser retratada. Mais do que a época, houve um tema, o da constituição do Estado independente e da nação, como entidade política soberana, nas ambiências da predominância de uma mentalidade liberal.

Se o personagem biografado, suas ações e idéias, no curso de trajetórias de vida, responderam pelas principais análises realizadas pelo autor, por intermédio de um narrador em terceira pessoa - o observador externo que enquadrava a cena e os protagonistas da história a ser contada -; essa última, nas suas circunstâncias dramatizadas pela própria narrativa, tornava-se o elemento definidor dos sentidos de cada uma das experiências da vida individual ali representada. Octávio Tarquínio procurava demonstrar o quanto os homens só se configuravam enquanto sujeitos por intermédio da história, entendida aqui 
como vivência social e cultural, circunscrita a uma duração. Cada uma das biografias mencionadas tiveram suas páginas saturadas por descrições interpretativas das circunstâncias que afetaram grupos, valores, práticas políticas na época em que a vida nacional, outra expressão utilizada por Octávio Tarquínio, definia sua fisionomia. Para o autor, a apreensão da vida nacional se daria pela mediação da vida de seus biografados, na perspectiva de enxergar nas fisionomias individuais a fisiognomia de coletividades históricas.

Cada uma das individualidades cujas fisionomias Octávio Tarquínio quis emoldurar em seus retratos em papel e letras assim veio a ser representada como parte de um conjunto de relações historicamente condicionadas. Nesses termos, a trajetória de Bernardo Pereira de Vasconcelos confundiu-se, a partir de um certo momento, com a trajetória do Regresso Conservador. A de Evaristo da Veiga ilustrou, de forma paradigmática, as propostas do reformismo liberal de viés moderado, tão adequado, como procurou reiterar o biógrafo, à consolidação da solda nacional. A vida de Feijó, mais vária e diversificada, garantiu o panorama de momentos ímpares na história da constituição do Estado Imperial, no Brasil, e da própria nação como corpo político autônomo: dos debates nas Cortes de Lisboa às Revoltas Liberais de 1842.

Em cada uma dessas biografias, Octávio Tarquínio procurou fazer a biografia da nação brasileira sobre as premissas de que a constituição dessa comunidade de homens, aglutinada pela partilha de valores, tradições culturais e experiências comuns, havia sido gestada pela ação de sujeitos que abraçaram os princípios políticos liberais. Mesmo ao modular os diversos projetos originários dessa matriz ideológica, como se quisesse ilustrar sua elasticidade histórica, o biógrafo posicionou-se, por vezes, fazendo suas as opiniões e credos de seus biografados. Na exemplaridade das condutas de seus protagonistas, Octávio Tarquínio procurou, por um lado, interpretar as ações dos que construíram o Estado nacional no momento de sua emergência histórica e, também, atualizar historicamente o valor do liberalismo político, em tempos em que esse, sofria tantas críticas e revisões.

Nesse aspecto, o tempo das Regências, distante cerca de cem anos, do momento em que Tarquínio de Sousa produziu seus primeiros textos biográficos, pareceu ser a paisagem histórica paradigmática, por excelência, para uma reflexão acerca dos usos do credo liberal na conformação de ordens políticas onde, o justo meio e o ideal de moderação pudessem guiar a conduta dos que desejavam modernizar e redescobrir a nação. Cumpre destacar, o quanto Octávio Tarquínio, autor/narrador em terceira pessoa, destacou a importância do debate 
parlamentar na condução da vida política daqueles dirigentes imperiais, monumentalizando tais experiências frente a tantas ameaças à consolidação da solda nacional. Talvez quisesse dizer aos leitores que a história de seu tempo presente - marcada, entre outros aspectos, pela a vigência do Estado Novo e suas práticas autoritárias, como a censura e o fechamento do Congresso - poderia ser diferente. Por mais que os homens estivessem presos às circunstâncias históricas, essas, numa certa proporção, se estabeleciam em conjunção com as suas vontades.

Como homem do seu tempo e na qualidade de letrado, Octávio Tarquínio viu, nas narrativas de vida de seus biografados, a possibilidade de construir análises históricas decifradoras e atualizadoras dos problemas nacionais. Diríamos que, sua forma particular de narrar a nação (Bhabha 1999: 1-7) produziu uma biografia do Estado nacional, no momento de sua emergência, centrada na proposta de figurar a dimensão trágica da história dos sujeitos individuais que assumiram postos na direção do mundo do governo (Mattos 1987: 109-129). A figuração da vida desse mundo do governo, por intermédio das trajetórias individuais de seus dirigentes, permitiu a Octávio Tarquínio apresentar a história da constituição do Estado nacional brasileiro sob a estreita 150 dependência da vontade de permanecer juntos ${ }^{6}$, posta à prova pelas próprias contingências da história, que o biógrafo e o historiador registrou na forma de um conhecimento que ordenava lembranças e esquecimentos providenciais.

Salta a impressão de que ao biografar dirigentes políticos da pretérita experiência de construção do Estado nacional, Octávio Tarquínio buscou falar do terreno movediço de sua contemporaneidade, visualizando na interpretação do passado algo esclarecedor sobre as impertinências e descontinuidades de suas vivências imediatas.

Cumpre destacar que, na busca de retratos em papel e letras que pudessem gerar nos leitores a impressão de que o biografado voltava a viver, na premissa de fazer da narrativa algo que pudesse figurar a dinâmica e o movimento das experiências vivenciadas pelo protagonista, Octávio Tarquínio quis imprimir

\footnotetext{
${ }^{6}$ Acreditamos que Octávio Tarquínio estabeleceu diálogos com a obra de Ernest Renan. Apesar de não fazer nenhuma menção direta, nas indicações bibliográficas de seus textos, o biógrafo e historiador parece ter se inspirado nas lições do pensador francês acerca do conceito de nação. Para Renan, a nação seria um princípio espiritual; o resultado de profundas complicações históricas; uma consciência moral criada pelos homens, subordinada a um rico legado de lembranças e ao desejo de viver juntos, a vontade de fazer valer a herança indivisa; a nação, como o indivíduo, seria o resultado de um longo passado de esforços, de sacrifícios e de devoções (...) (Renan 1997: 12-43).
} 
sobre seus textos um certo valor literário, a partir da utilização de elementos da narrativa do romance - a graça, a leveza, a maneira de apresentar o assunto. Na perspectiva de manter Sherazade viva, e nisso seguindo parcialmente a receita proposta por Maurois, Octávio Tarquínio materializava, em suas narrativas biográficas, mais uma de suas dimensões modernas.

\section{De Strachey a Dilthey}

Firmando um estilo, o de autor de biografias históricas em diálogo com o que essas pudessem materializar de exemplos de uma reinvenção da história nacional e de atualização do próprio fazer biográfico, Octávio Tarquínio de Sousa veio a publicar José Bonifácio, em 1945, e A vida de D. Pedro I, em 1952, essa última recebida entusiasticamente pela crítica literária da época.

O projeto de reunir suas biografias históricas e outros textos de sua autoria na forma de uma coleção, em 1958, inegavelmente, perenizou os trabalhos de Octávio Tarquínio de Sousa sob uma clave diferente daquela que havia, nos anos quarenta, o qualificado como o historiador das Regências. Com a História dos Fundadores, novos sentidos foram imputados a cada uma de suas biografias de dirigentes políticos imperiais, em função do pertencimento a um conjunto particular - a coleção -, marcadamente comprometida com a análise de um tema e de uma época, qual seja: a emergência e a consolidação do Estado Imperial brasileiro.

Se esse aspecto foi recorrente nos comentários dos que analisaram a coletânea lançada em 1958, cabe, destacar, o quanto, nesse momento, o autor explicitou referências à Wilhelm Dilthey nas suas perspectivas de relacionar narrativa biográfica e escrita da história.

Na Introdução à História dos Fundadores do Império do Brasil, Octávio Tarquínio declarou que, quando esteve em suas possibilidades, sua tarefa biográfica inspirou-se em boa parte das lições de Dilthey (Sousa 1960: v. I-14) ${ }^{7}$. De fato, como pudemos constatar, suas possibilidades estiveram associadas à leitura de El mundo historico (Dilthey 1944). Na biblioteca de Octávio Tarquínio de Sousa, a primeira edição em espanhol do referido livro, datada

\footnotetext{
${ }^{7} \mathrm{Na}$ introdução à História dos Fundadores Octávio Tarquínio, do mesmo modo que havia feito no prefácio à primeira edição de Diogo Antônio Feijó, explicitou os valores que informavam suas concepções sobre biografia e história. Não caberia nesse artigo detalhálas. Vale mencionar o quanto, naquele momento, 1958, conceitos das formulações historistas vieram a compor o eixo de suas argumentações.
} 
de 1944, ainda guarda as anotações e os marcadores de páginas, pequenas nesgas de papel amarelecidas, a denotar os vestígios de leitura do autor.

Entre tantas marcações, cumpre destacar, nos limites desse artigo, aquelas em que o leitor Octávio Tarquínio deparou-se com as análises do filósofo sobre a biografia. Em seis páginas, Dilthey se dispôs a expressar suas considerações sobre o caráter científico e sobre a dimensão artística da narrativa biográfica. Octávio Tarquínio assinalou grande parte do texto; parecia ter encontrado sintéticos argumentos de autoridade para suas inquietudes de biógrafo.

Cabe relembrar que tais considerações de Dilthey foram originalmente escritas em 1910 (Dilthey 1944: 417-418). O estatuto da escrita biográfica, traduzido na questão de ser ela ou não parte integrante da história, na sua dimensão de conhecimento científico, estava exatamente sendo posto em xeque, face a transformações relacionadas à emergência de uma biografia moderna. Como filósofo empenhado na tarefa de realizar a crítica da razão histórica, Dilthey percebeu, de forma acurada, o alcance epistemológico e metodológico do debate em torno do estatuto da biografia, situando-o no campo das determinações da própria cientificidade do conhecimento histórico.

Como sua crítica da razão histórica não só visava a fundamentar as ditas Ciências do Espírito, com destaque entre elas para a História, como igualmente se desdobrava em uma filosofia da vida, com implicações sobre os usos da psicologia e da hermenêutica (Amaral: 1997; Gadamer 1998: 27-38), a discussão sobre o estatuto da biografia representou, nas formulações diltheyanas, a possibilidade de exemplificar o quanto suas idéias resolveriam certas antinomias, cuja existência, na avaliação do filósofo, se devia à impropriedade de querer conhecer a vida humana por intermédio de valores que serviriam unicamente às ditas Ciências da Natureza. Pelo seu pertencimento ao campo da história, nesse aspecto, às Ciências do Espírito, por sua dimensão de narrativa de vida, por sua funcionalidade entre as obras que se prestavam a decifrar o mundo histórico, a biografia, segundo Dilthey, como resultado de uma certa metodologia de produção do conhecimento, poderia ser qualificada como obra de arte, possuindo, todavia, um caráter científico, ditado pelas suas interfaces com o conhecimento histórico. O texto diltheyano, nessas argumentações, se desenvolveu sobre um jogo de oposições e complementaridades, onde ao fim, a expressão obra científica de arte apontou para a ambigüidade intrínseca do fazer biográfico (Dilthey 1944: 270-276).

A par dessas argumentações, talvez possamos compreender o encontro entre o leitor Octávio Tarquínio e o filósofo alemão. O biógrafo Tarquínio de 
Sousa, cuja produção intelectual havia se baseado em rigorosa pesquisa e crítica documental, traduzidas em textos onde avultaram os cuidados com a forma literária, visualizou nas considerações diltheyanas sobre a biografia, as lições que, talvez, havia muito, fossem procuradas, e que, em certa medida, aprofundavam, em bases epistemológicas, valores decantados, de forma mais ligeira, nas formulações de Strachey e de seu divulgador maior, André Maurois. O historismo de Wilhelm Dilthey complementou, em larga medida, a trajetória de um autor que pautou grande parte de sua produção no cruzamento entre identidades individuais e individualidades históricas.

Nas palavras de Sérgio Buarque de Holanda, Octávio Tarquínio quis abordar a História a partir dos homens que fizeram a História (Holanda 1988: 11). Assim o fez, em especial, no momento de reunir as biografias produzidas ao longo de 15 anos, na forma da História dos Fundadores, firmando um lugar e um valor para os usos da biografia na elaboração do conhecimento histórico.

Um dos últimos vestígios de leitura de Octávio Tarquínio sobre El mundo historico, nos auxiliou no traçado de algumas derradeiras considerações:

(...) A vida se dá unicamente na vivência, na compreensão e na captação histórica. (...) Estamos abertos às possibilidades, já que o sentido e o significado surgem primeiramente no homem e na sua história. Mas não no homem individual, senão no homem histórico. Pois o homem é algo histórico...(Dilthey 1944: 318)

A premissa diltheyana do homem como ser histórico e da sua vida como algo cujo sentido só poderia ser captado por meio da História, delegou ao texto biográfico, na sua acepção de escrita da vida de um homem, um valor intrínseco entre narrativas voltadas para o estudo do que "realmente havia acontecido". As narrativas biográficas, contudo, deveriam configurar-se como textos que ao decifrarem seus protagonistas como sujeitos individuais, viessem, acima de tudo, apresentá-los como homens históricos. Nesse ponto, o encontro do biógrafo e historiador Octávio Tarquínio de Sousa com as formulações historistas do pensador alemão Wilhelm Dilthey permitiram ao autor brasileiro reiterar e lapidar o valor de suas narrativas biográficas para a escrita da história do Estado Nacional, em terras brasileiras. José Bonifácio, D. Pedro I, Feijó, Evaristo da Veiga, Bernardo de Vasconcelos foram todos, nos retratos em papel e letras de Octávio Tarquínio de Sousa, homens históricos. 


\section{Bibliografia}

ABREU, Alzira Alves de . "I Congresso Brasileiro de Escritores". In Dicionário Histórico-biográfico Brasileiro. Rio de Janeiro: Editora da FGV, CPDOC, 2001. V. II, pp. 1535-6.

AMARAL, Maria Nazaré de Camargo Pacheco. Dilthey: um conceito de vida e uma pedagogia. São Paulo: Perspectiva; Editora da Universidade de São Paulo, 1987.

BHABHA, Homi K. Nation and Narration. London; New York: Routledge, 1999.

CAVALHEIRO, Edgard. Biografias e biógrafos. Curitiba; São Paulo; Rio de Janeiro: Editora Guaíra Limitada, 1943.

DILTHEY, Wilhelm. El mundo historico. Tradução de Eugenio Imaz. México: Fondo de Cultura Economica, 1944.

EVERDELL, William R.. Os primeiros modernos. As origens do pensamento do século XX. Tradução de Cynthia Cortes e Paulo Soares. Rio de Janeiro; São Paulo: Record, 2000.

GADAMER, Hans-Georg. "Extensão e limites da obra de Wilhelm Dilthey". In FRUCHON, Pierre (org). O problema da consciência histórica. Rio de Janeiro: Editora da FGV, 1998, pp. 27-38.

HOLANDA, Sérgio Buarque de. "Octávio Tarquínio e Pedro I, a História a partir dos homens”. In SOUSA, Octávio Tarquínio. Bernardo Pereira de Vasconcelos. Belo Horizonte: Itatiaia; São Paulo: Editora da Universidade de São Paulo, 1988, pp. 11-14.

HUGHES, Stuart. Consciousness and Society. The reorientation of European Social Thought 1890-1930. Revised Edition. New York: Vintage Books, 1977.

LIMA, Alceu Amoroso. "Biografias”. In Estudos. $4^{a}$ Série. Rio de Janeiro: Edição do Centro Dom Vital, 1931, pp. 165-177.

MANDÉLENAT, Daniel. La biographie. Paris: PUF, 1984.

MATTOS, Ilmar Rohloff de. O Tempo Saquarema. São Paulo: Hucitec; Brasília, DF: INL, 1987.

MAUROIS, Andre. Aspects of Biography. Translate by Sydney Castle Roberts. New York: D Appleton \& Company, 1929.

MOMIGLIANO, Arnaldo. The development of Greek Biography. Expanded edition. Cambridge; London: Harvard University Press, 1993. 
RENAN, Ernest. “O que é uma nação?”. In ROUANET, Maria Helena (org.). Nacionalidade em questão. Rio de Janeiro: UERJ, 1997, pp. 12-43. (Cadernos da Pós/Letras).

SALIBA, Elias Thomé. "Reinvenção da história". In Brasil-brasis: cousas notáveis e espantosas (Olhares Modernistas). Lisboa: Comissão Nacional para as Comemorações dos Descobrimentos Portugueses, 2000, pp 43-49.

SOUSA, Octávio Tarquínio de. Bernardo Pereira de Vasconcelos e seu tempo. Rio de Janeiro: Livraria José Olympio Editora, 1937. (Coleção Documentos Brasileiros, v. 3) . Evaristo da Veiga. São Paulo: Companhia Editora Nacional, 1939. (Coleção Brasiliana, v. 157. Biblioteca Pedagógica Brasileira) Diogo Antônio Feijó. Rio de Janeiro: Livraria José Olympio Editora, 1942. (Coleção Documentos Brasileiros, v. 35) José Bonifácio. Rio de Janeiro: Livraria José Olympio Editora, 1945. (Coleção Documentos Brasileiros, v. 51) A vida de D. Pedro I. Rio de Janeiro: Livraria José Olympio Editora, 1952, 3 volumes. (Coleção Documentos Brasileiros, v.71) José Bonifácio. Rio de Janeiro: Livraria José Olympio Editora, 1960, v.1. ( História dos Fundadores do Império do Brasil, 10 volumes) STRACHEY, Lytton. Rainha Vitória. Tradução de Luciano Trigo. Rio de Janeiro; São Paulo: Record, 2001. 